\title{
Perbandingan pengaruh promosi kesehatan menggunakan media audio dengan media audio-visual terhadap perilaku kesehatan gigi dan mulut siswa SD
}

\author{
${ }^{1}$ Eko A. Papilaya \\ ${ }^{2}$ Kustina Zuliari \\ ${ }^{2}$ Juliatri \\ ${ }^{1}$ Kandidat Skripsi Program Studi Pendidikan Dokter Gigi Fakultas Kedokteran \\ ${ }^{2}$ Program Studi Pendidikan Dokter Gigi Fakultas Kedokteran \\ Universitas Sam Ratulangi Manado \\ Email: eko.papilaya@yahoo.co.id
}

\begin{abstract}
Dental health education conducted to the elementary school students is one of the promotive efforts to increase oral and dental health, however, it needs an appropriate media. This study was aimed to evaluate the difference between health promotion using audio media and using audio-visual media to dental health behavior of elementary school students. This was a quasy experimental study using questionnaire as the instrument. This study was conducted among elementary school students of Sekolah Dasar Inpres at Tiwoho North Minahasa. There were 56 students as respondents obtained by using simple random sampling method. The result of independent $\mathrm{T}$-test showed a difference between the average behavior value of the audio group and of the audio-visual group $(\mathrm{p}=0.004)$. Conclusion: There was a significant difference between health promotion using audio media and using audio-visual media to care dental health behavior among elementary school students.
\end{abstract}

Keywords: health promotion, audio, audio-visual

\begin{abstract}
Abstrak: Promosi kesehatan gigi dan mulut pada siswa sekolah dasar merupakan salah satu upaya promotif dalam meningkatkan kesehatan gigi dan mulut anak. Untuk melakukan hal tersebut diperlukan penggunaan media yang tepat. Penelitian ini bertujuan untuk mengevaluasi perbandingan pengaruh promosi kesehatan menggunakan media audio dengan media audio-visual terhadap perilaku kesehatan gigi dan mulut pada siswa SD. Penelitian dilakukan di SD Inpres Tiwoho Minahasa Utara, dengan jenis penelitian quasy eksperimental menggunakan kuesioner. Jumlah responden sebanyak 56 siswa diperoleh dengan teknik simple random sampling. Hasil uji statistik independent T-test menunjukkan perbedaan antara nilai rerata kelompok audio-visual dan kelompok audio $(\mathrm{p}=0,004)$. Simpulan: Terdapat perbedaan bermakna antara promosi kesehatan menggunakan media audio dengan media audio-visual terhadap perilaku pemeliharaan kesehatan gigi dan mulut pada siswa SD.
\end{abstract}

Kata kunci: promosi kesehatan, audio, audio-visual

Kesehatan gigi dan mulut merupakan hal yang penting dalam kehidupan setiap individu termasuk pada anak, karena gigi dan gusi yang rusak dan tidak dirawat akan menyebabkan rasa sakit, gangguan pengunyahan, dan dapat mengganggu kesehatan tubuh lainnya. Masalah gigi dan mulut pada anak dapat juga berpengaruh pada pertumbuhan dan perkembangan anak. Kondisi kesehatan gigi susu akan turut menentukan pertumbuhan gigi tetap anak. Disamping itu anak-anak merupakan kelompok umur yang rentan 
terhadap penyakit. Anak yang memiliki masalah pada kesehatan gigi dan mulutnya, dapat terganggu kualitas hidupnya, padahal anak merupakan aset bangsa untuk pembangunan di masa yang akan datang.

Berdasarkan Riset Kesehatan Dasar (RISKESDAS) tahun 2007 dan tahun 2013 menunjukkan persentase masyarakat Indonesia yang memiliki masalah gigi dan mulut meninggkat dari $23,2 \%$ menjadi $25,9 \%$. Data tersebut menunjukkan masih banyak masyarakat Indonesia yang kurang memperhatikan kesehatan gigi dan mulut. Data dari Riskesdas Tahun 2007 dan 2013 juga menunjukkan persentase perilaku penduduk usia 10 tahun ke atas yang menyikat gigi dengan benar dari 7,3\% di tahun 2007 menurun menjadi $2,3 \%$ di tahun $2013 .{ }^{1}$ Hal ini menjadi masalah, karena salah satu cara pencegahan yang efektif terhadap terjadinya penyakit gigi dan mulut yakni melalui tindakan menyikat gigi. Terbentuknya perilaku menyikat gigi individu yang benar didasari oleh bekal informasi individu yang diperoleh antara lain melalui promosi kesehatan gigi dan mulut.

Promosi kesehatan gigi dan mulut merupakan suatu proses pemberian informasi yang timbul atas dasar kebutuhan kesehatan gigi dan mulut yang bertujuan untuk menghasilkan kesehatan gigi dan mulut yang baik dan meningkatkan taraf hidup. Dalam promosi kesehatan gigi dan mulut, individu memperoleh pengalaman atau informasi melalui berbagai media promosi kesehatan gigi dan mulut. ${ }^{2}$

Media merupakan salah satu hal yang perlu diperhatikan dalam melakukan promosi kesehatan. Media yang biasa dipakai dalam promosi kesehatan yaitu media audio, media visual dan media audio-visual. Media audio visual merupakan media yang baik untuk digunakan, karena media tersebut melibatkan lebih banyak indra dalam proses pembelajaran. Video animasi ialah salah satu contoh media audio-visual. $^{3}$

Desa Tiwoho di Minahasa Utara merupakan daerah pesisir dengan status ekonomi masyarakatnya masih menengah ke bawah dan tenaga kesehatan gigi yang sedikit, memungkinkan pengetahuan masyarakat tentang kebersihan gigi dan mulut juga sangat kurang, dan belum pernah ada penelitian tentang kesehatan gigi dan mulut di daerah tersebut menjadi hal yang dipertimbangkan dalam memilih desa Tiwoho menjadi tempat penelitian. SD Inpres Tiwoho merupakan sekolah dasar yang ada di desa Tiwoho, di SD Inpres Tiwoho belum ada program UKGS, sehingga SD Inpres Tiwoho dipilih untuk menjadi lokasi penelitian. Penelitian ini bertujuan untuk mendapatkan perbandingan pengaruh promosi kesehatan menggunakan media audio dengan media audio-visual terhadap perilaku kesehatan gigi dan mulut siswa SD Inpres Tiwoho Minahasa Utara.

\section{BAHAN DAN METODE PENELITIAN}

Jenis penelitian ini ialah quasi experimental dengan pre-test and post-test grup design. Penelitian dilaksanakan di SD Inpres Tiwoho pada bulan April-Oktober 2016.

Responden penelitian yaitu siswa SD Inpres Tiwoho berusia 9-12 tahun berjumlah 56 siswa yang telah memenuhi kriteria inklusi, diperoleh dengan metode simple random sampling. Responden dibagi menjadi dua kelompok yaitu kelompok audio dan kelompok audio-visual, masing-masing berjumlah 28 siswa. Instrumen penelitian ini yaitu kuesioner. Pengolahan dan analisis data menggunakan SPSS versi 16 yang disajikan dalam bentuk tabel.

\section{HASIL PENELITIAN}

Karakteristik responden penelitian ini dapat dilihat pada Tabel 1 dan 2 .

Tabel 1. Distribusi karakteristik responden berdasarkan jenis kelamin

\begin{tabular}{lcccc}
\hline \multirow{2}{*}{$\begin{array}{c}\text { Jenis } \\
\text { kelamin }\end{array}$} & \multicolumn{2}{c}{ Media audio } & \multicolumn{2}{c}{$\begin{array}{c}\text { Media audio- } \\
\text { visual }\end{array}$} \\
\cline { 2 - 5 } & $\mathrm{n}$ & $\%$ & $\mathrm{n}$ & $\%$ \\
\hline Laki-laki & 15 & 54 & 16 & 57 \\
Perempuan & 13 & 46 & 12 & 43 \\
Total & 28 & 100 & 28 & 100 \\
\hline
\end{tabular}

Tabel 2. Distribusi karakteristik responden berdasarkan usia

\begin{tabular}{ccccc}
\hline $\begin{array}{c}\text { Usia } \\
\text { (Tahun) }\end{array}$ & \multicolumn{2}{c}{ Media audio } & \multicolumn{2}{c}{$\begin{array}{c}\text { Media } \\
\text { audio-visual }\end{array}$} \\
\cline { 2 - 5 } & $\mathrm{n}$ & $\%$ & $\mathrm{n}$ & $\%$ \\
\hline 9 & 7 & 25 & 6 & 21 \\
10 & 7 & 25 & 7 & 25 \\
11 & 5 & 18 & 5 & 18 \\
12 & 9 & 32 & 10 & 36 \\
Total & 28 & 100 & 28 & 100 \\
\hline
\end{tabular}


Tabel 3. Hasil penilaian perilaku kesehatan gigi dan mulut

\begin{tabular}{cccccc}
\hline \multirow{2}{*}{ Kelompok } & Kategori & \multicolumn{2}{c}{$\begin{array}{c}\text { Media } \\
\text { audio }\end{array}$} & \multicolumn{3}{c}{$\begin{array}{c}\text { Media } \\
\text { audio- } \\
\text { visual }\end{array}$} \\
\cline { 3 - 6 } & & $\mathrm{n}$ & $\%$ & $\mathrm{n}$ & $\%$ \\
\hline Sebelum & Baik & 14 & 50 & 13 & 46 \\
& $\begin{array}{c}\text { Kurang } \\
\text { baik }\end{array}$ & 14 & 50 & 15 & 54 \\
& Baik & 14 & 50 & 20 & 71 \\
Sesudah & $\begin{array}{c}\text { Kurang } \\
\text { baik }\end{array}$ & 14 & 50 & 8 & 29 \\
& & & & & \\
\hline
\end{tabular}

Tabel 4. Uji normalitas kelompok audio-visual

\begin{tabular}{ccccc}
\hline & \multicolumn{3}{c}{ Shapiro Wilk } \\
\cline { 3 - 5 } & Kelompok & Statistik & Df & Sig \\
& & & & $(\mathrm{p})$ \\
Hasil & Sebelum & 0,883 & 28 & 0,55 \\
& Sesudah & 0,904 & 28 & 0,27 \\
\hline
\end{tabular}

Tabel 5. Uji normalitas kelompok audio

\begin{tabular}{ccccc}
\hline & & \multicolumn{3}{c}{ Shapiro Wilk } \\
\cline { 3 - 5 } & Kelompok & Statistik & Df & $\begin{array}{c}\text { Sig } \\
(\mathrm{p})\end{array}$ \\
\hline \multirow{3}{*}{ Hasil } & Sebelum & 0,887 & 28 & 0,39 \\
& Sesudah & 0,887 & 28 & 0,39 \\
\hline
\end{tabular}

Tabel 6. Uji paired T-test

\begin{tabular}{cccc}
\hline & & Mean & Sig (p) \\
\hline Audio- & Sebelum & 42,14 & 0,000 \\
visual & Sesudah & 46,64 & \\
& Sebelum & 41,93 & \\
Audio & Sesudah & 42,68 & 0,297 \\
\hline
\end{tabular}

Tabel 7. Uji Independent T-test

\begin{tabular}{ccccc}
\hline Kelompok & n & Mean & $\begin{array}{c}\text { Mean } \\
\text { selisih }\end{array}$ & $\begin{array}{c}\text { Sig } \\
(\mathbf{p})\end{array}$ \\
\hline Audio-visual & 28 & 46,42 & 16,9 & 0,004 \\
Audio & 28 & 29,48 & & \\
\hline
\end{tabular}

\section{BAHASAN}

Pada penelitian ini didapatkan responden berjenis kelamin laki-laki pada kelompok audio-visual (57\%) lebih banyak dibandingkan dengan responden berjenis kelamin perempuan dengan (43\%). Demikian pula pada kelompok audio, responden berjenis kelamin laki-laki (54\%) lebih banyak dibandingkan responden berjenis kelamin perempuan $(46 \%)$.

Berdasarkan usia, responden berusia 12 tahun yang terbanyak baik pada kelompok audio (32\%) maupun kelompok audio-visual $(36 \%)$.

Tabel 3 menunjukkanahwa sebelulm perlakuan responden kelompok audio-visual dengan kategori kurang baik (54\%) lebih banyak dibandingkan responden dengan kategori baik (46\%) sedangkan pada kelompok audio, responden dengan kategori kurang baik dan kategori baik sama banyak. Hasil ini menunjukkan bahwa siswa SD Inpres Tiwoho masih memiliki perilaku pemeliharaan kesehatan gigi dan mulut yang kurang baik. Hasil pada Tabel 3 juga menunjukkan peningkatan dari pretest ke posttest pada kelompok audio-visual yang menunjukkan bahwa promosi kesehatan gigi dan mulut menggunakan media audio-visual memiliki kemampuan dalam memperbaiki perilaku pemeliharaan kesehatan gigi dan mulut (kategori baik menjadi 71\%).

Tabel 4 menunjukkan nilai signifikansi dari uji normalitas kelompok audio-visual menggunakan Shapiro-Wilk. Nilai signifikansi pretest kelompok audio-visual yaitu 0,55 dan nilai signifikansi posttest yaitu 0,27 . Tabel 5 menunjukan hasil uji normalitas kelompok audio. Nilai signifikansi pretest dan posttest yaitu 0,39 . Data yang diperoleh menunjukkan bahwa data terdistribusi normal. ${ }^{4}$

Berdasarkan uji paired T-test pada kelompok audio-visual didapatkan hasil terjadi perubahan perilaku pemeliharaan kesehatan gigi dan mulut dengan nilai rerata 42,14 sebelum dilakukan promosi kesehatan gigi dan mulut, dan 46,64 setelah dilakukan promosi kesehatan gigi dan mulut $(\mathrm{p}=0,000<0,05)$. Hasil uji paired T-test pada kelompok audio juga terjadi perubahan perilaku pemeliharaan kesehatan gigi dan mulut dengan nilai rerata 41,93 sebelum dilakukan promosi kesehatan gigi dan mulut, dan 42,68 setelah dilakukan promosi kesehatan gigi dan mulut $(\mathrm{p}=0,297)$ (Tabel 6). Jika dilihat dari nilai rerata kedua kelompok maka dapat dikatakan kelompok audio-visual memiliki nilai yang lebih baik dari pada kelompok audio.

Hasil uji Independent T-test menunjukkan terdapat perbedaan bermakna dari selisih jumlah skor antara pemberian promosi kesehatan gigi dan mulut menggunakan media audio-visual dan media audio dalam meningkatkan perilaku pemeliharaan kesehatan 
gigi dan mulut $(\mathrm{p}=0,004<0,05)$ (Tabel 7). Data ini juga menunjukkan perbedaan nilai rerata pada kelompok audio-visual dengan kelompok audio. Nilai rerata kelompok audiovisual sebesar 46,42 sedangkan nilai rerata kelompok audio sebesar 29,48. Dalam hal ini peneliti berpendapat bahwa pemberian promosi kesehatan gigi dan mulut menggunakan media audio-visual lebih baik dalam meningkatkan perilaku pemeliharaan kesehatan gigi dan mulut anak dibandingkan menggunakan media audio. Hal ini dikarenakan media audio-visual memiliki kelebihan yaitu dapat menstimulasi efek gerak sehingga terlihat lebih menarik dan lebih mudah merangsang pemahaman siswa. Media audio-visual dapat membuat anak melihat dan mendengar secara bersamaan materi yang diberikan. ${ }^{5}$

Hasil penelitian ini sejalan dengan penelitian oleh Andriany ${ }^{6}$ pada anak SDN 24 Banda Aceh mengenai perbandingan efektifitas media penyuluhan poster dan kartun animasi terhadap pengetahuan kesehatan gigi dan mulut. Penelitian tersebut menggunakan pretest and posttest group design dengan jumlah sampel 42 orang, dibagi menjadi dua kelompok yang diberikan penyuluhan menggunakan media poster dan media animasi. Hasil penelitian menunjukkan animasi yang merupakan media audio-visual lebih efektif dalam meningkatkan pengetahuan kesehatan gigi siswa. Penelitian yang dilakukan oleh Nurani $^{7}$ tentang pengaruh penyuluhan kesehatan gigi dan mulut melalui audio-visual terhadap kemandirian gosok gigi pada anak prasekolah menunjukkan adanya perubahan perilaku kemandirian anak dalam menggosok gigi.

Perubahan perilaku menurut teori stimulus organisme terjadi karena dengan adanya stimulus yang diberikan terhadap organism maka organisme bereaksi sehingga terjadi perubahan perilaku. ${ }^{8}$ Teori Kurt Lewis juga menyatakan perubahan perilaku terjadi kerena adanya dorongan atau stimuli berupa penyuluhan atau informasi. ${ }^{9}$ Stimulus yang baik diberikan terhadap organisme maka semakin baik pula perubahan perilaku dari organisme tersebut. Stimulus yang baik ialah stimulus yang dapat melibatkan banyak indra dari organisme karena semakin banyak indra yang dipakai untuk menerima dan mengelola stimulus tersebut semakin besar kemungkinan informasi itu dimengerti dan dipertahankan dalam ingatan. ${ }^{10}$

Penyuluhan menggunakan media audiovisual membuat penerima penyuluhan menggunakan lebih banyak indra dibandingkan dengan penyuluhan yang hanya menggunakan media audio, Media audio-visual mendorong penerimanya untuk menggunakan indra pendengar dan indra pengelihatan agar informasi dapat diterima dengan baik.

\section{SIMPULAN}

Dari hasil penelitian terhadap siswa SD Inpres Tiwoho yang berusia 9-12 tahun dapat disimpulkan bahwa terdapat perbedaan bermakna antara promosi kesehatan menggunakan media audio dengan media audio-visual terhadap perilaku pemeliharaan kesehatan gigi dan mulut pada siswa SD.

\section{SARAN}

1. Perlu dilakukan penelitian sejenis dengan menggunakan media promosi kesehatan gigi dan mulut yang berbeda atau dengan menambahkan media promosi kesehatan gigi dan mulut yang lain sebagai pembanding sehingga bisa diketahui jenis media yang paling baik untuk membantu penyampaian informasi lewat promosi kesehatan gigi dan mulut.

2. Diharapkan Puskesmas di Kecamatan Wori Desa Tiwoho bisa menggunakan hasil penelitian ini sebagai bahan pertimbangan dalam upaya preventif dan promotif dalam bidang kesehatan gigi dan mulut untuk meningkatkan derajat kesehatan gigi dan mulut masyarakat di wilayah kerjanya.

\section{DAFTAR PUSTAKA}

1. Departemen Kesehatan Republik Indonesia. Laporan hasil riset kesehatan dasar (Riskesdas) nasional 2013. Jakarta: Badan Penelitian dan Pengembangan Kesehatan, 2013; p. 111-7.

2. Maryam S. Promosi Kesehatan. Jakarta: EGC, 2014; p.18.

3. Rahayu RD. Pengaruh video kartun terhadap kemampuan kognitif pada anak kelompok B di TK Terpadu Al-Hidayah II ds Bakung kec Udanawu kab Blitar. Jurnal Mahasiswa Teknologi Pendidikan. 2013;2(4):50.

4. Siswanto. Metodologi Penelitian Kesehatan dan Kedokteran. Yogyakarta: Bursa Ilmu, 
2014; p. 309.

5. Jafar CP. Pengaruh pendidikan kesehatan melalui audiovisual terhadap perilaku personal hygiene anak kelas IV di SDN 2 Jambidan Banguntapan Bantul. Yogyakarta: Program Studi Ilmu Keperawatan Sekolah Tinggi Ilmu Kesehatan Aisyiyah; 2015.

6. Andriany. Perbandingan efektifitas media penyuluhan poster dan kartun animasi terhadap pengetahuan kesehatan gigi dan mulut. Journal of Syiah Kuala Dentistry Society. 2016;1(1):65-72.
7. Nurani. Pengaruh penyuluhan kesehatan melalui audiovisual terhadap kemandirian gosok gigi anak prasekolah di TK Aba Tegalsari Yogyakarta. Yogyakarta: Program Studi Ilmu Kesehatan Aisyiyah; 2015.

8. Maulana HDJ. Promosi Kesehatan. Jakarta: EGC, 2009; p. 232.

9. Kholid A. Promosi Kesehatan dengan Pendekatan Teori Perilaku Media dan Aplikasinya. Jakarta: Raja Grafindo Persada, 2012; p.120.

10. Supiyati, Ambarwati ER. Promosi Kesehatan. Yogyakarta: Pustaka Rihama, 2012; p.75. 